\title{
Mesh Free MOdeling OF THE CURVEd BEAM STRUCTURES
}

\author{
Kozulic, V.; Gotovac, B. \& Sesartic, R.
}

Abstract: This paper presents a numerical model for linear static analysis of the arch structures which is based on a mesh free method. The concept of the mesh free method is in establishing a system of algebraic equations for the whole problem domain without traditional discretization into finite elements. In this work, the collocation method is used to develop the numerical model by using Fupn(x) basis functions.

Here, the procedure for direct solving the system of three differential equations is presented. Because this system of equations arises from the complete formulation of equilibrium conditions of the curved beam, numerical solution includes the coupled influences of bending, shear and axial forces. By this formulation, negative influences of the shear and membrane locking effects are completely eliminated. The presented numerical model is illustrated by examples of the arch structures with constant curvature for various cases of loading and boundary conditions.

Key words: arch beam, mesh free method, basis functions, collocation method, shear and membrane locking
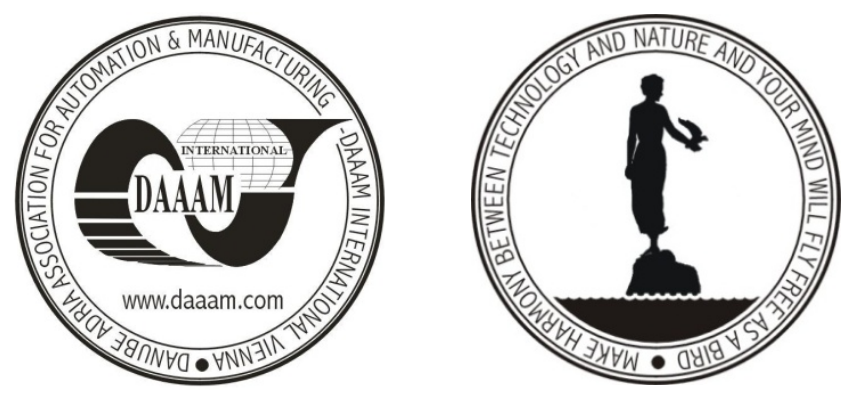

Authors' data: Prof. Kozulic, V[edrana]; Prof. Gotovac, B[laz]; Sesartic, R[enata], University of Split, Faculty of Civil Engineering and Architecture, Matice hrvatske 15, 21000, Split, HR, vedrana.kozulic@gradst.hr, blaz.gotovac@gradst.hr, renata.sesartic@gradst.hr

This Publication has to be referred as: Kozulic, V[edrana]; Gotovac, B[laz] \& Sesartic, R[enata] (2008). Mesh Free Modeling of the Curved Beam Structures, Chapter 34 in DAAAM International Scientific Book 2008, pp. 395-408, B. Katalinic (Ed.), Published by DAAAM International, ISBN 978-3-901509-66-7, ISSN 17269687, Vienna, Austria

DOI: $10.2507 /$ daaam.scibook.2008.34 